\title{
Optimalisasi Biaya Distribusi Beras Subsidi Dengan Model Transshipment
}

\section{Optimizing the Cost of Distribution of Subsidized Rice Using the Transshipment Model}

\author{
Gumilar Nur Muhamad*, Rizqi Fadilah, Muchammad Fauzi \\ Jurusan Teknik Industri, Fakultas Teknik, Universitas Widyatama \\ Neglasari Cibeunying Kaler, \\ JL. Cikutra No. 204 A, Sukapada, Cibeunying Kidul, Kota Bandung, Jawa Barat 40125 \\ Email: gumilarnm@gmail.com, Rizqi_dila@yahoo.com, muchammad.fauzi@widyatama.ac.id
}

\begin{abstract}
ABSTRAK
Salah satu masalah transportasi dalam studi kasus ini adalah distribusi beras bersubsidi. PT. XYZ ingin mendistribusikan barang-barangnya dengan biaya minimum. Oleh karena itu, perlu untuk menyelesaikan masalah transportasi menggunakan model transshipment sehingga optimasi biaya distribusi dapat direalisasikan. Solusi untuk masalah transportasi dimulai dengan mengubah tabel transportasi ke tabel transhipment kemudian menemukan solusi menggunakan aplikasi LINGO. Hasil penelitian ini menunjukkan bahwa beras bersubsidi harus dikirim oleh setiap distributor ke agen di desa dengan tujuan optimal dan biaya pengiriman sebesar Rp. 18.317.000.
\end{abstract}

Kata Kunci: Transshipment, Distribusi, Optimalisasi, Beras.

\section{ABSTRACT}

One of the transportation problems in this case study is the distribution of subsidized rice. PT. XYZ wants to distribute its goods at a minimum cost. Therefore, it is necessary to solve transportation problems using the transshipment model so that optimization of distribution costs can be realized. The solution to the transportation problem starts with changing the transportation table to the transshipment table then finding a solution using the LINGO application. The results of this study indicate that subsidized rice must be sent by each distributor to an agent in the village with the optimal destination and shipping costs of Rp. 18.317.000.

Keyword : Transshipment, Distribution, Optimization, Rice.

\section{Pendahuluan}

Perusahaan yang bergerak dibidang distribusi harus dapat mengefektifkan penggunaan jalur distribusi dalam menghemat pengeluaran biaya transportasi. Model transhipment merupakan suatu masalah transportasi dimana sebagian atau seluruh barang yang diangkut dari sumber tidak langsung dikirim ke tempat tujuan tetapi melalui transit. Dengan demikian tujuan utama masalah transhipment adalah untuk menentukan jumlah barang yang akan dikirim dari suatu sumber ke tempat tujuan akhir meskipun melalui tempat transit dengan ketentuan kebutuhan pada tempat tujan akhir bisa terpenuhi, dengan total biaya yang seminimum mungkin. Model transhipment dapat diselesaikan dengan beberapa metode yaitu metode least cost, metode north west corner dan metode
Vogel's approximation method dan menggunakan aplikasi LINGO.

PT. XYZ merupakan salah satu perusahaan yang bergerak dibidang distribusi beras subsidi (berperan sebagai sumber) yang ditujukan untuk beberapa kantor desa (agen) yang ada di wilayah Kabupaten Bandung Barat. PT. XYZ diharuskan untuk dapat melakukan pengambilan keputusan yang matang sehingga setiap keputusan yang diambil dapat memberi masukan terhadap kelangsungan perusahaan. Salah satu keputusan penting yang harus diambil adalah mengenai proses pendistribusian barang dari pabrik ke desa-desa yang menjadi tujuan.

\section{Distribusi}

Menurut Tjiptono (2008), distribusi dapat diartikan sebagai kegiatan pemasaran yang berusaha 
memperlancar dan mempermudah penyampaian barang dan jasa dari produsen kepada konsumen, sehingga penggunaannya sesuai dengan yang diperluaskan (jenis, jumlah, harga, tempat, dan saat dibutuhkan), dalam proses pendistribusian produk terdapat beberapa kendala yang sering dihadapi oleh perusahaan, baik kendala secara internal maupun kendala eksternal. Kendala internal dapat berupa kebijakan yang dikeluarkan oleh perusahaan yang menyangkut distribusi dan pelayanan, serta sarana-prasarana penunjang dalam proses distribusi, sedangkan kendala eksternal dapat berasal dari cara pendistribusian dan tempat yang dituju yaitu konsumen.

\section{Model Ranshipment}

Model transhipment merupakan perluasan dari masalah transportasi. Model transhipment adalah model transportasi yang memungkinkan dilakukannya pengiriman barang (komoditas) secara tidak langsung, dimana barang dari suatu sumber dapat berada pada sumber lain atau tujuan lain sebelum mencapai tujuan akhirnya. Ekren dan Heragu (2018) menyatakan bahwa penyatuan proses pendistribusian telah banyak digunakan yang bertujuan untuk mengurangi biaya dan meningkatkan layanan kepada konsumen sehingga dikembangkan proses pendistribusian lanjutanya itu pendistribusian dengan model transhipment. Model transhipment merupakan suatu masalah transportasi dimana sebagian atau seluruh barang yang diangkut dari sumber tidak langsung dikirim ketempat tujuan tetapi melalui transit. Selanjutnya, mengubah tabel transhipment ke model transportasi umum.

\section{LINGO}

LINGO merupakan program komputer yang dapat digunakan untuk menyelesaikan permasalahan optimasi yang bervariasi menjadi lebih mudah dan efisien. Menurut Taha, Program LINGO menyediakan paket terintegrasi yang mencakup bahasa yang kuat untuk mengekspresikan model optimasi, lingkungan fitur lengkap untuk membangun dan editing masalah, dan satu set builtin solver yang mampu secara efisien memecahkan model-model optimasi.

\section{Metode Penelitian}

Metodelogi penelitian adalah penjabaran langkah-langkah yang berkaitandalam melakukan penelitian ini. Adapun langkah-langkah tersebut dapat dilihat pada Gambar 1.

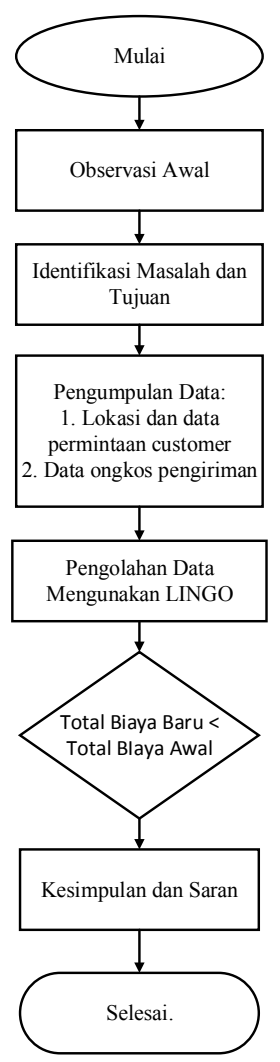

Gambar 1. Flowchart Metodelogi Penelitian

Langkah awal dimulai dengan identifikasi masalah kemudian dilanjutkan dengan mencari studi literatur yang bersumber dari buku, skripsi, jurnal dan sebaginya yang relevan dengan permasalahan yang ada. Pengumpulan data yang diperlukan untuk proses selanjutnya, hal yang diperlukan antara lain rute pengiriman awal, data pelanggan, serta ongkos kirim. Pengolahan data dilakukan menggunakan aplikasi LINGO. Langkah selanjutnya adalah analisis dan memberikan kesimpulan hasil dari metode ini.

\section{Hasil dan Pembahasan}

\section{Sumber Data}

Penulis menggunakan data primer berupa data historis tahun 2020 bulan Januari pada PT.XYZ yang merupakan salah satu perusahaan perdistribusian beras subsidi di Kabupaten Bandung Barat yang mampu menyuplai $28.710 \mathrm{~kg}$ beras subsidi, mempunyai 3 distributor dan tujuannya yaitu agen beras di 6 desa tujuan. Data distribusi pengiriman dari sumber ke tujuan dapat dilihat dari tabel-tabel berikut ini:

Tabel 1. Biaya Pengiriman Beras Subsidi dari Sumber ke Distrbutor

\begin{tabular}{lll} 
Dari & Ke & Tarif/Kirim \\
\hline 1 & 2 & 3065 \\
\hline 1 & 3 & 3150 \\
\hline 1 & 4 & 2950 \\
\hline
\end{tabular}


Satuan tarif: Ratusan ribu rupiah

Tabel 2. Distribusi Pengiriman Beras Subsidi dari Distrbutor ke Tujuan

\begin{tabular}{lllll}
\hline Tujuan & $\begin{array}{l}\text { Permi } \\
\text { ntaan } \\
(\mathrm{Kg})\end{array}$ & $\begin{array}{l}\text { Tarif/Ki } \\
\text { rim } \\
\text { Dari-2 }\end{array}$ & $\begin{array}{l}\text { Tarif/Ki } \\
\text { rim } \\
\text { Dari-3 }\end{array}$ & $\begin{array}{l}\text { Tarif/Kir } \\
\text { im } \\
\text { Dari-4 }\end{array}$ \\
\hline 5 & 2.610 & 2261 & 1672 & 1890 \\
\hline 6 & 2.700 & 2270 & 1690 & 1875 \\
\hline 7 & 5.940 & 2594 & 2338 & 1895 \\
\hline 8 & 3.960 & 2396 & 1942 & 1885 \\
\hline 9 & 6.300 & 2630 & 2410 & 1920 \\
\hline 10 & 7.200 & 2720 & 2590 & 1905 \\
\hline
\end{tabular}

Satuan tarif: Ratusan ribu rupiah

Biaya Pengiriman diperoleh dari data yang diberikan oleh PT.XYZ.

3. Waktu dan Tempat

Penelitan ini telah dilakukan di perusahaan distibusi beras subsidi di Kabupaten Bandung Barat PT. $\mathrm{XYZ}$.

4. Variabel Penelitian

Variabel penelitian menggunakan variabel kuantitatif yaitu jumlah beras $(\mathrm{kg})$ dan tarif pengiriman (Rp. perkirim).

5. Kerangka Penelitian

Secara deskriptif jalur pengirman dari sumber ke desa tujuan di tunjukan oleh gambar 2 berikut:

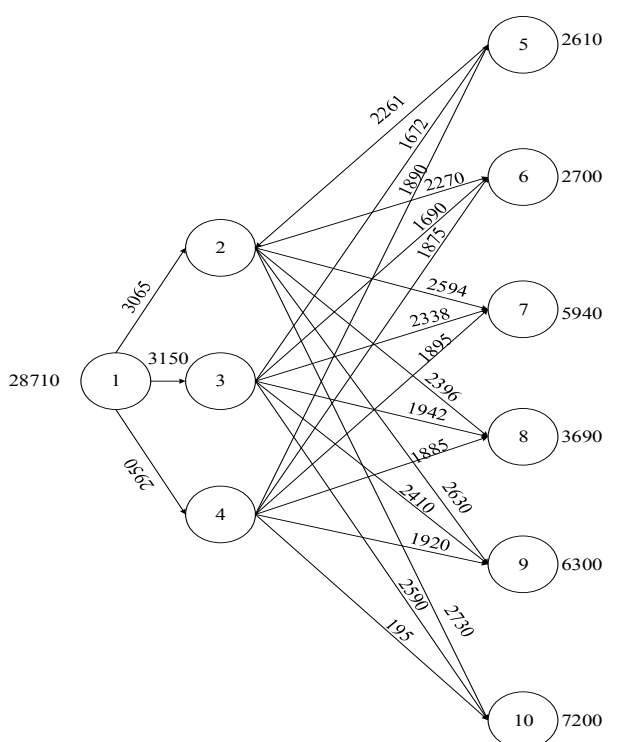

Gambar 2. Penggambaran alur distribusi dari Sumber sampai Tujuan.

Berikut tabel distribusi PT.XYZ:

Tabel 3. Tabel Distribusi Pengiriman Beras Subsidi dari Sumber ke Distrbutor

\begin{tabular}{|c|c|c|c|c|}
\hline \multirow{2}{*}{$\begin{array}{l}\mathrm{Ke} \\
\text { Dari }\end{array}$} & \multicolumn{3}{|c|}{ Distributor } & \multirow{2}{*}{$\begin{array}{l}\text { Supp } \\
\mathrm{y}\end{array}$} \\
\hline & 2 & 3 & 4 & \\
\hline Sumbe & 3065 & 3150 & 2950 & 28.71 \\
\hline
\end{tabular}

1

0

Tabel 4. Tabel Distribusi Pengiriman Beras Subsidi dari Distributor ke Agen di Desa Tujuan

\begin{tabular}{|c|c|c|c|c|}
\hline \multirow{2}{*}{$\begin{array}{l}\text { Dari } \\
\mathrm{Ke}\end{array}$} & \multicolumn{3}{|c|}{ Distibutor } & \multirow{2}{*}{ Demand } \\
\hline & 2 & 3 & 4 & \\
\hline 5 & 2261 & 1672 & 1890 & 2.610 \\
\hline 6 & 2270 & 1690 & 1875 & 2.700 \\
\hline 7 & 2594 & 2338 & 1895 & 5.940 \\
\hline 8 & 2396 & 1942 & 2950 & 3.960 \\
\hline 9 & 2630 & 2410 & 1920 & 6.300 \\
\hline 10 & 2720 & 2590 & 1905 & 7.200 \\
\hline Total & & & & 28.710 \\
\hline
\end{tabular}

6. Pengolahan Data Menggunakan Metode Transhipment.

Penyelesaian dengan metode Transhipment ini bertujuan untuk mengetahui banyaknya beras subsidi yang harus dikirim dari tiap-tiap distributor ke desa-desa tujuan sehingga mendapatkan biaya yang minimum dengan bantuan software LINGO 11.0. Berikut adalah hasil pembentukan rute menggunakan metode Transhippment yang digunakan oleh PT.XYZ dengan alat bantu software LINGO 11.0

Langkah awal pengolahan data adalah dengan membuat formulasi dalam program LINGO sesuai dengan fungsi tujuan dan batasan masalah, sebagai berikut:

1) Pada sets diberi inputan matriks dan satuan

2) Selanjutnya pada data diberi inputan matriks permintaan dari setiap desa tujuan, biaya pengiriman dari sumber ke distributor dan biaya pengiriman dari distibutor ke desa tujan.

3) Setelah itu pilih tombol solve

4) Hasil dari penggunaan software LINGO 11.0 didapatkan output sebagai berikut:

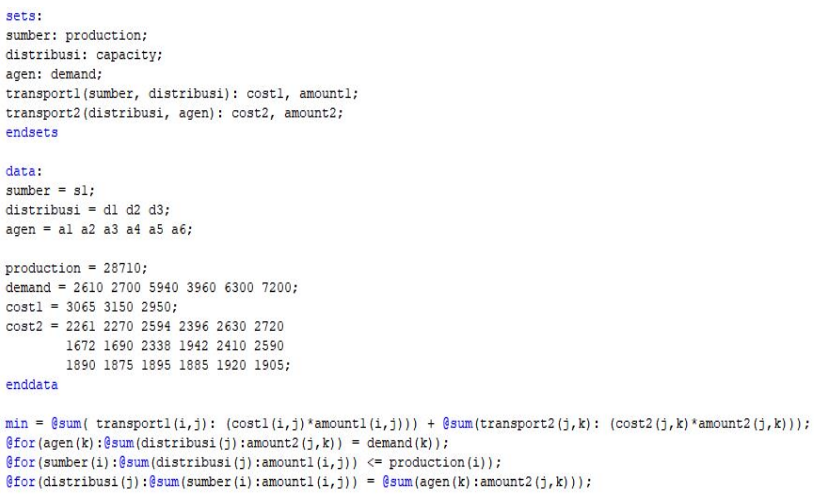


Gambar 3. Syntax Model

\begin{tabular}{|c|c|c|c|}
\hline \multicolumn{2}{|c|}{ Variable } & $\begin{array}{l}\text { Value } \\
\text { Ving }\end{array}$ & Reduced Cost \\
\hline PRODUCTION & No ( S1) & 28710.00 & 0.000000 \\
\hline CAPACITY & $\mathrm{Y}(\mathrm{D} 1)$ & 0.000000 & 0.000000 \\
\hline CAPACITY & Y ( D2) & 0.000000 & 0.000000 \\
\hline CAPACITY & Y ( D3) & 0.0000000 & 0.000000 \\
\hline DEMAND & $\mathrm{D}(\mathrm{A} 1)$ & 2610.000 & 0.000000 \\
\hline DEMAND & $\mathrm{D}(\mathrm{A} 2)$ & 2700.000 & 0.000000 \\
\hline DEMAND & $D(\mathrm{~A} 3)$ & 5940.000 & 0.000000 \\
\hline DEMAND & $\mathrm{D}(\mathrm{A} 4)$ & 3960.000 & 0.000000 \\
\hline DEMAND & $\mathrm{D}(\mathrm{A} 5)$ & 6300.000 & 0.000000 \\
\hline DEMAND & $D(\mathrm{~A} 6)$ & 7200.000 & 0.000000 \\
\hline $\cos 11$ ( $\mathrm{s} 1$ & 1, D1) & 3065.000 & 0.000000 \\
\hline $\operatorname{cosT1}(\mathrm{s} 1$ & 1, D2) & 3150.000 & 0.000000 \\
\hline $\cos 11$ ( $\mathrm{s} 1$ & 1, D3) & 2950.000 & 0.000000 \\
\hline AMOUNT1 ( $\mathrm{S} 1$ & 1, D1) & 0.000000 & 0.000000 \\
\hline AMOUNT1 ( $\mathrm{S1}$ & 1, D2) & 2610.000 & 0.000000 \\
\hline AMOUNTI ( $\mathrm{S1}$ & 1, D3) & 26100.00 & 0.000000 \\
\hline $\operatorname{cosT} 2(\mathrm{D} 1$ & (1, A1) & 2261.000 & 0.000000 \\
\hline $\operatorname{cosT2}(\mathrm{D} 1$ & 1, A2) & 2270.000 & 0.000000 \\
\hline $\operatorname{cosT2} 2$ ( D1 & $\begin{array}{lll}1 & \text { A3) }\end{array}$ & 2594.000 & 0.000000 \\
\hline $\operatorname{cosT2}(\mathrm{D} 1$ & 1, A4) & 2396.000 & 0.000000 \\
\hline $\operatorname{cosT2}(\mathrm{D} 1$ & 1, AS) & 2630.000 & 0.000000 \\
\hline $\operatorname{cosT2} 2(\mathrm{D} 1$ & 1, A6) & 2720.000 & 0.000000 \\
\hline $\operatorname{cosT} 2(\mathrm{D} 2$ & 2, A1) & 1672.000 & 0.000000 \\
\hline $\operatorname{cosT2}(\mathrm{D} 2$ & $2, \mathrm{~A} 2)$ & 1690.000 & 0.000000 \\
\hline $\operatorname{COST} 2(\mathrm{D} 2$ & 2, A3) & 2338.000 & 0.000000 \\
\hline $\operatorname{cosT} 2(\mathrm{D} 2$ & $2, \mathrm{~A} 4)$ & 1942.000 & 0.000000 \\
\hline $\operatorname{cosT} 2(\mathrm{D} 2$ & 2, A5) & 2410.000 & 0.000000 \\
\hline $\cos 21$ D2 & $2, \mathrm{A6})$ & 2590.000 & 0.000000 \\
\hline $\operatorname{cosT} 2$ ( D3 & 3, A1) & 1890.000 & 0.000000 \\
\hline $\operatorname{cosT2} 2(\mathrm{D} 3$ & 3, A2) & 1875.000 & 0.000000 \\
\hline $\operatorname{cosT2}(1)$ & 3, A3) & 1895.000 & 0.000000 \\
\hline $\operatorname{cosT2}\left(D_{3}\right.$ & 3, A4) & 1885.000 & 0.000000 \\
\hline $\operatorname{cosT2} 2(\mathrm{D} 3$ & 3, A5) & 1920.000 & 0.000000 \\
\hline $\operatorname{cosT2}(\mathrm{D} 3$ & $3, \mathrm{~A} 6)$ & 1905.000 & 0.000000 \\
\hline AMOUNT2 ( D1 & 1, A1) & 0.000000 & 504.0000 \\
\hline AMOUNT2 ( D1 & 1, A.2) & 0.000000 & 510.0000 \\
\hline AMOUNT2 ( D1 & (1, A3) & 0.0000000 & 814.0000 \\
\hline AMOUNT2 ( D1 & $1, \mathrm{~A} 4)$ & 0.000000 & 626.0000 \\
\hline AMOUNT2 ( D1, & A5) & 0.000000 & 825.0000 \\
\hline AMOUNT2 ( D1, & $\therefore A 6)$ & 0.0000000 & 930.0000 \\
\hline AMOUNT2 ( D2, & 2, A1) & 2610.000 & 0.000000 \\
\hline AMOUNT2 ( D2, & $\therefore$ A2) & 0.0000000 & 15.00000 \\
\hline AMOUNT2 ( D2, & 2. A3) & 0.0000000 & 643.0000 \\
\hline AMOUNT2 ( D2, & 2, A4) & 0.0000000 & 257.0000 \\
\hline AMOUNT2 ( D2, & 2. A5) & 0.0000000 & 690.0000 \\
\hline AMOUNT2 ( D2, & 2. A6) & 0.000000 & 885.0000 \\
\hline AMOUNT2 ( D3, & 3, A1) & 0.000000 & 18.00000 \\
\hline AMOUNT2 ( D3, & $3, \mathrm{~A} 2)$ & 2700.000 & 0.000000 \\
\hline AMOUNT2 ( D3, & 3, A3) & 5940.000 & 0.000000 \\
\hline AMOUNT2 ( D3, & $3, \mathrm{~A} 4)$ & 3960.000 & 0.000000 \\
\hline AMOUNT2 ( D3, & $3, \mathrm{~A} 5)$ & 6300.000 & 0.000000 \\
\hline AMOUNT2 ( D3, & $3, \mathrm{~A} 6)$ & 7200.000 & 0.000000 \\
\hline
\end{tabular}

Berikut tabel distribusi setelah pengolahan data dan didapatkan solusi dari LINGO:

Tabel 4. Tabel Distribusi Pengiriman Beras Subsidi dari Sumber ke Distrbutor

\begin{tabular}{|c|c|c|c|c|}
\hline \multirow{2}{*}{ Dari $^{\mathrm{Ke}}$} & \multicolumn{3}{|c|}{ Distributor } & \multirow{2}{*}{ Supply } \\
\hline & 2 & 3 & 4 & \\
\hline \multirow{2}{*}{ Sumber } & 3065 & 3150 & 2950 & \multirow{2}{*}{28.710} \\
\hline & 0 & 2610 & 26100 & \\
\hline
\end{tabular}

Tabel 5. Tabel Distribusi Pengiriman Beras Subsidi dari Distributor ke Agen di Desa Tujuan

\begin{tabular}{|c|c|c|c|c|}
\hline \multirow{2}{*}{$\begin{array}{l}\text { Dari } \\
\text { Ke }\end{array}$} & \multicolumn{3}{|c|}{ Distibutor } & \multirow{2}{*}{ Demand } \\
\hline & 2 & 3 & 4 & \\
\hline \multirow{2}{*}{5} & 2261 & 1672 & 1890 & \multirow{2}{*}{2.610} \\
\hline & 0 & 2610 & 0 & \\
\hline \multirow{2}{*}{6} & 2270 & 1690 & 1875 & \multirow{2}{*}{2.700} \\
\hline & 0 & 0 & 2700 & \\
\hline \multirow{2}{*}{7} & 2594 & 2338 & 1895 & \multirow{2}{*}{5.940} \\
\hline & 0 & 0 & 5940 & \\
\hline \multirow{2}{*}{8} & 2396 & 1942 & 2950 & \multirow{2}{*}{3.960} \\
\hline & 0 & 0 & 3960 & \\
\hline \multirow{2}{*}{9} & 2630 & 2410 & 1920 & \multirow{2}{*}{6.300} \\
\hline & 0 & 0 & 6300 & \\
\hline 10 & 2720 & 2590 & 1905 & 7.200 \\
\hline
\end{tabular}

\begin{tabular}{cccc}
\multicolumn{2}{c}{0} & 0 & 7200 \\
\hline Total & & & 28.710 \\
\hline & Total biaya pengiriman yang & dikeluarkan
\end{tabular}
dari sumber ke distributor sebesar: Rp. 6.100.000. Total biaya pengiriman yang dikeluarkan dari distributor ke agen di desa tujuan sebesar: Rp. 12.217.000. Sehingga total biaya pengiriman sebesar Rp. 18.317.000.

\section{Kesimpulan}

Kesimpulan dari penelitian ini adalah didapatkan hasil untuk pengoptimalan pengiriman beras subsidi ke agen-agen di desa tujuan menggunakan metode transhipment, PT.XYZ hanya melalui Distributor 3 dan Distributor 4. Dengan total beras yang dikirim Distributor 3 sebanyak $2.610 \mathrm{~kg}$ dan Distributor 4 sebanyak $26.100 \mathrm{~kg}$. Hasil optimal biaya pengiriman yang didapatkan adalah sebesar Rp. 18.317.000.

\section{Daftar Pustaka}

H. Taha, Operation Research An Introduction, Ed.8, Pearson Education Inc, New Jersey. 2007.

I. W. Ardhyani, Mengoptimalkan Biaya Pakan Ternak dengan menggunakan Metode Transportasi (Studi Kasus di PT. X Krian), Teknika Engine.

M. Zulhijah, Pengoptimalan Biaya Distribusi Barang Dengan Menggunakan Metode Transportasi Pada PT. Yusindo Mitra Persada, 2017.

Mustadin, Optimalisasi Teknik Riset Operasional Untuk Penghematan Biaya Transportasi Pengiriman Buah Kelapa Sawit Dengan Metode North West Corner (Studi Kasus PT. Agro Muko). Jursima (Jurnal Sistem Informasi Dan Manajemen, Sekolah Tinggi Ilmu Manajemen Dan Komputer Gici - Batam, No.2, Vol.4,1-8, 2016

R. Coughlan dan W. Jian. Lingo The Modeling Language and Optimizer. Chicago: LINDO Systems Inc. 2018.

Zulfikarijah, Fien. 2008. Pemodelan dalam Riset Operasi. Bandung: Institut Teknologi Bandung. 